\title{
Editorial
}

URBAN DESIGN International (2008) 13, 57-60. doi:10.1057/udi.2008.17

\section{The origin of the liveable street concept}

The notion of 'livable streets' was emphasised by Appleyard in his book of the same name (Appleyard, 1981). Appleyard was reflecting on attempts to tame traffic in cities around the world, and this process of trying to humanise our environments, against the constant growth in levels of traffic in cities, still continues today.

Appleyard's own work started from his now famous review of the quality of life enjoyed by residents in three streets in San Francisco, which had similar forms, but different levels of traffic. It moved on to look at how differences in income, age and vulnerability affected people's ability to use and enjoy streets. The work then discussed the 'early street battles' (p. 145), where quality of life issues were used as a basis for reducing the impact of traffic on domestic life within urban areas. These themes reflect closely the focus of current work on the issue.

Much of this thinking was a reaction to Buchanan's conceptualisation of how to accommodate traffic in towns (Ministry of Transport, 1963), which saw the imposition of both 'distributory networks' and 'environmental areas' upon established urban environments that had evolved prior to motorised traffic. Many people applauded the latter and the attempts made to stop rat running, but found that the former came to dominate the urban experience, as major roads divorced from their context were introduced, destroying the urban fabric and patterns of community or neighbourhood life. Appleyard, in contrast, celebrated early attempts at traffic restraint through management or design and drew particular attention to the then recently publicised woonerfen in the Netherlands (Royal Dutch Touring Club, 1977), where the introduction of shared surfaces in residential streets were giving space back to non-car users, while also turning out to be safer than traditional streets.
This work is important as it represents an early, clear statement about the importance of social lives within and across streets, and is a precursor, in the English language, to a wide range of literature and thinking about, and subsequently practices in the design and management of traffic routes to improve liveability against a rising tide of car ownership and, more importantly, use.

\section{Interdisciplinarity and creating the conditions for liveable streets}

As an area of public policy the ability to deliver liveable streets, as initially defined by Appleyard, is wrapped up in a government's ability to

- control development,

- design and manage travel networks,

- manage travel demand and the resulting traffic,

- promote alternatives to the private car for travel,

- embrace a full understanding of how urban design affects driver and pedestrian behaviour as a result of particular urban forms and approaches to highway design and landscaping,

- legislate for, or allow activities other than traffic use within highway space,

- manage and enforce speed control, and

- invest in, manage and maintain an appropriate public realm and highway infrastructure.

Delivering liveable streets is inherently interdisciplinary, with its need to embrace all subdisciplines relating to the planning, design, and development of the built environment and transport infrastructure, and certainly there are different types of knowledge and skill that must be brought to the task. Underlying all initiatives and perspectives, however, is the demand to find space for human life and social activity within an environment that is under constant pressure to accommodate more traffic and highways. 


\section{The case for liveable streets}

The starting point for many subsequent works in this area is the sense that something has been lost from our streets when they are given over to traffic. This is possibly difficult to substantiate if lives have merely shifted from the localised street lives of the past to the more mobile lifestyles of today. Hasn't more been gained from the freedom to travel that we now enjoy? Well yes, but we also know that the effects are unequal. The freedom to move out of town and commute back into town for work means you now impose your traffic upon the people who stayed put. The freedom that a majority enjoy to drive has a knock-on effect on those left behind using less viable forms of public transport, where costs increase and timetables slacken. The freedom you enjoy to drive quickly reduces the liberty of a child to play outside their home, or puts elderly or disabled people off going to their local shops or parks. People who stay central to things must endure your congestion, noise and atmospheric pollution, while they might also have to tolerate your car parked, taking up potential development sites or (now privatised) street space that might once have been used for other public activities or planting. Journeys across town that were once easy on foot or by bike become more unpleasant as space is progressively dedicated to wider routes as traffic demand has to be accommodated. And of course, as more people travel to destinations by car, and businesses are designed around wide car-based catchments, so more car parking becomes necessary for businesses to be viable, and pedestrians and pedestrian-based environments become more difficult to support.

Public debates are full of the implications of these general trends: the loss of local small businesses and the formation of retail deserts, sedentary lifestyles and the growing incidence of obesity, loss of neighbourhood institutions, shops and services, lack of neighbourliness and severance between neighbourhoods, loss of play space or opportunity around the home and intolerance or fear of children in the public realm, alienation of the elderly and people who are disabled from their local environments, higher casualty rates or the reduction in street activity as a result of their poor use by pedestrians, degradation of historic environments and along distributing routes as a result of traffic and its infrastructure or more general environmental pollution and its global implications.

\section{The adoption of the liveable street concepts internationally}

Traditional patterns of urbanism in Europe, supported by public policy, were early to buck the trend towards car-oriented development and dependency, and consequently have tended to take street environments seriously for a longer period of time. New developments tend to build on the dense patterns of urbanism that have been conserved and there remains evidence of good investment in well-used public transport systems that are culturally part of the way of life. Here we see new developments with a concern for delivering a strong urban form embracing pedestrian permeability, exploring shared surfaces and traffic calming, while the highway and parking standards remain tight. We also see the New Urbanism and Smart Growth movements in the US reinvesting in a concern for walkability and the social life of the urban environment, a set of ideas that has successfully been exported around the world. In countries like England and parts of Australia we see the national or state government's commitment to an urban renaissance or sustainable patterns of development through a variety of interrelated policy initiatives that has seen planning, highways and design policies attempting to (re)create a sense of urbanism and walkability.

Internationally we do see, however, variation in how the liveable street concepts are being interpreted as domestic, essentially private, aspirations clash with the urban designers' principles of urbanism. Densities of development, in particular, considered normal in the US and Australia fall well below those expected in Europe, even if the same objectives of sustainability or walkability are being pursued; and this seems to affect the extent to which liveable streets initiatives might be considered as more or less radical and ultimately effective.

\section{Recent research related to the liveable street agenda}

This edition of Urban Design International pulls together a number of papers that reflect on how 
these issues are being thought about and how they are affecting the design and management of more liveable streets internationally, but in particular within the US, Australia, the UK, the Netherlands and Switzerland. The papers focus on a range of interrelated themes that in combination demonstrate how a concern for street life and street use might be approached from a number of perspectives, while each builds upon an aspect of the liveable streets agenda so well established by Appleyard over 25 years ago.

Karsten reflects on the extent to which street activity, previously rejected within Dutch society, has been progressively reappropriated in the Netherlands by middle-class residents returning to live within older, denser, more central, former working-class neighbourhoods, showing how the urban design measures often associated with liveable street initiatives must support a concurrent tendency or demand for street use by sections of a wider society.

Sauter and Huettenmoser explore similar themes and techniques to Appleyard in his comparative study of three streets, by comparing the impact of traffic volume on the quantity and quality of street life in five streets in Basel, Switzerland. They discuss how the quieter streets offer the greatest potential for a richer community life and examine how this has been achieved.

Mackett, Achuthan and Titheridge report on their work developing software to evaluate the accessibility of environments for people who, due to a physical disability, are less mobile. The work looks, in particular, at the small details of streetscape that, for example, can make crossing the road or getting into a building difficult. Using a case study from St. Albans in the UK, the work shows how changes to these details can make significant differences to how such people might use the streets and gain access to the services that they need.

Ewing and Lane then examine the extent to which traffic calming has been adopted in the US. They argue that the US is a little behind, for example, states in Europe, and note in particular that calming measures are not necessarily developed in association with an integrated package of measures designed to create environments really fit for walking or cycling. They note, however, some lessons emerging from some cities where more radical and effective measures are being adopted.

Curtis and Tiwari then discuss the important process of turning arterial strips into what they call 'activity corridors'. Noting that arterial routes within the urban environment have often been important commercial and residential frontages in historic cities, the article examines strategic work in Perth, Western Australia undertaken to help turn important roads into vibrant 'walkable' streets by creating an operational strategy for development, which can be adopted by planning and highways professionals.

Biddulph then reviews the impact of the UK's home zone initiatives that saw the legal designation in the UK of streets equivalent to the Dutch woonerf and funding, in England at least, for a series of demonstration projects across the country. It is noted in particular that the initiatives have had an important impact on national highway guidance on standards for residential roads, although the extent to which local authorities might adopt the new guidance appears to be quite varied.

Finally, Hamilton-Baillie, a UK practitioner, discusses the role of shared space projects, and in particular notes the importance of work in Fiesland in the north of the Netherlands by Hans Monderman, and its impact on how street space is being conceived in parts of the UK. Shared space projects are relatively radical and involve removing signage, road markings and variations in surface from relatively welltrafficked environments, including commercial streets and relatively busy junctions. The concept is certainly at the cutting edge of practice where old assumptions about streets space, street use and safety are being challenged in the interests of the pedestrian and more vulnerable street users.

These papers show the diverse range of settings in which attempts are being made to make our streets more liveable, taking on the agenda that Appleyard originally discussed. They show how the concepts are spreading globally in at least the developed world, and that the ideas are being applied to the whole spectrum of highways within the urban area. It is fair to say that the spread of these ideas 
and practices still seems to be regarded with some scepticism in some quarters and that the prospect of their wider adoption still has someway to go, but practice is evolving to catch up with the theory.

\section{References}

Appleyard, D. (1981) Livable Streets. Berkeley: University of California Press.

Ministry of Transport. (1963) Traffic in Towns: A Study of the Long Term Problems of Traffic in Urban Areas (The Buchanan Report). London: HMSO.

Royal Dutch Touring Club. (1977) Woonerf. The Hague: RDTC.

Mike Biddulph 